\title{
Study on Network Mass Incidents Involving College and University Students*
}

\author{
Jidong ZHANG \& Weijun ZHOU, Kun JIANG \\ Tianjin University of Technology, Tianjin, China
}

\begin{abstract}
With the popularization of network technology, the network mass incidents involving college and university students have been the important aspect in college and university management. Through undergoing an empirical study on parts of colleges and universities in Tianjin this passage analyzes the cause and the nature of incidents, the way of spread and the harm, and it also provides detailed advice and proposal. KEYWORD: College and University; Network; Mass Incidents
\end{abstract}

\section{MEANING OF STUDY}

The network public opinion in college and university students' mass incidents can be applied to evaluate whether the campus is harmony or not and will affect college and university students' thinking and behavior at a large extent. As we all know, college and university is the important place to cultivate the builders and successors of socialist, and it can make people become moral, individual, physical, aesthetical. and model sound personality, also campus is the place to exercise will and quality, and train practical ability, foster the world outlook of life, also it is the important place to learn scientific knowledge and master social skills. Therefore, it is necessary to maintain a harmony, stable and safe campus environment and create an atmosphere with fine cultural opinion in campus as well as preventing the harm form mass incidents even its occurrence.

The independent analysis about the course of network mass incidents involving college and university students can help people to understand and solve these incidents in an overall perspective. With different causes even results, the process and characteristic of mass incidents from the start to the outbreak and in the end also can be analyzed and concluded from the collecting cases to provide reference for the targeted control of process and the intervention without delay.

\section{DATA ANALYSIS}

\subsection{Sample Analysis}

University, Nankai University, Tianjin University of Technology, Tianjin Normal University, Tianjin Polytechnic University, Tianjin Medical University and Tianjin Youth Vocational college have recovered 581 valid questionnaires with $96.8 \%$ recovery rate. The sample surveys the type of college and university, student, major, the ratio of gender, and the grade on 15 secretaries or directors that responsible for students' affairs and 24 students that involved in the 41 incidents and randomly selects 20 students from these colleges and universities to interview independently to collect valid materials.

\subsection{The Use of Internet}

The survey shows that the use of cellphone, tabloid and computer reaches $72.5 \%$ and that of micro blog, Renren and QQ is 95\%, and the time surfing on the Internet about 5 hours every day exceeds $83 \%$.

\footnotetext{
*'The Study on the Strategies of Ideological and Political Education Based on the Evolution Mechanism of Network Mass Incidents Involving College and University Students", projected by the general philosophical and scientific planning project in Tianjin. No: TJJX13-041
} 
Table 1 The Study Analysis about the Sample of Network Mass Incidents Involving College and University Students in Tianjin

\begin{tabular}{|c|c|c|c|c|c|c|c|c|}
\hline Variables & \multicolumn{2}{|c|}{ Level of college and university } & \multicolumn{2}{c|}{ Ratio of Gender } & \multicolumn{4}{c|}{ Type of Students } \\
\hline Groups & $\begin{array}{c}\text { Colleges and } \\
\text { Universities directly } \\
\text { under the Ministry of } \\
\text { Education }\end{array}$ & $\begin{array}{c}\text { Ordinary } \\
\text { colleges and } \\
\text { Universities }\end{array}$ & $\begin{array}{c}\text { Vocational } \\
\text { colleges }\end{array}$ & Female & Male & $\begin{array}{c}\text { Students } \\
\text { Cadres }\end{array}$ & $\begin{array}{c}\text { Communist } \\
\text { Party } \\
\text { Members }\end{array}$ & $\begin{array}{c}\text { Ordinary } \\
\text { Students }\end{array}$ \\
\hline Number & 153 & 337 & 91 & 312 & 269 & 153 & 146 & 282 \\
\hline Variables & \multicolumn{3}{|c|}{ Type of Majors } & \multicolumn{5}{c|}{ Grade } \\
\hline Group & Liberal Arts & Science & Technology & Freshman & Sophomore & Junior & Senior & Graduate \\
\hline Number & 214 & 192 & 175 & 120 & 120 & 116 & 115 & 110 \\
\hline
\end{tabular}

Table 2 The Inducing Factors and the Nature of College and University Students' Network Mass Incidents in Tianjin

\begin{tabular}{|c|c|c|c|c|c|}
\hline & Positive & Neutral & Negative & Total & Percentage \\
\hline Campus (Classroom) & 10 & 1 & 13 & 24 & $58.54 \%$ \\
\hline Social Incidents & 3 & 2 & 3 & 8 & $19.51 \%$ \\
\hline Dormitory Incidents & 0 & 3 & 3 & 6 & $14.63 \%$ \\
\hline Canteen Incidents & 0 & 1 & 2 & 3 & $7.32 \%$ \\
\hline Total & 13 & 7 & 21 & 41 & $100 \%$ \\
\hline Percentage & $31.71 \%$ & $17.07 \%$ & $51.22 \%$ & $100 \%$ & \\
\hline
\end{tabular}

From this, we know most students have the capacity and demand to receive and spread the network information and they are happy to update their states and comment or spread the events around them as well as public their opinions to be opinion leaders in the network. No matter the food quality and price in canteen or the environment in campus even the sanitation in dormitory, all can be the topics they make comments, criticize or praise. Compared with previous use of computer, cellphone's popularization leads the terminal publishing and information spreading that based on cellphone or network to be more sudden and different to control. Therefore, colleges and universities should pay more attention to this platform or channel, which is cellphone or network.

\subsection{Types of Incidents}

The survey shows that the causes that result in the network mass incidents include the country's policy or international diplomacy even measures from colleges and universities, such as, the increasing price of food, adjustment and contradiction in dormitory, evaluation for teachers and the safety of campus. Hence no matter the conflicts of ideology or interests among countries or personal trivial things, all may result in network mass incidents and should be the key points that college and university administrators should concern. Based on that, they should distinguish the nature of incident at the first time whether it is positive, negative or neutral, know student's thought and their actual thought, and suppose the incident that may happen to take measures in advance before it happens.

\subsection{Inducing Factors}

To further analyze the inducing factors and nature of incidents, the author spent 2 months interviewing the administrators and teachers who are responsible for students affairs from the 7 colleges and universities above and finally concluded the number, nature and inducing factors of incidents in this colleges and universities in recent years (See Table 2). From the table above, we know the sites that occurred incidents focused on campus (classroom), society, dormitory and canteen with the percentage of $58.54 \%, 19.51 \%, 14.63 \%$ and $7.32 \%$ respectively. Therefore, every college and university should strengthen the monitoring for every corner in campus and the oversight in dormitory and canteen. And most negative incidents involving college and university students, such as, the assessment of scholarship and grant, conflicts in dormitory, increased price of food in canteen and the evaluation for teachers, occurred in the campus with the percentage as $61.9 \%$ and $76.92 \%$ positive events also occurred in campus, such as, party for welcoming freshmen and pray activities for disaster area. Therefore, colleges and universities are the primary inducing factor of network mass incidents. And at the same time the social events also affect the safety and stability of campus.

\subsection{Media of Information Spreading}

Here it refers to the large scale information spreading on the internet caused by trigger events which results in baneful influence in society. Spreading media includes real society (pass from mouth to mouth among students), internet (short 
massage service, Tieba $<$ Chinese communication platform >, QQ, micro blog, Wechat, news), and interleaving of the above two. Analysis of the 41 network incidents involving mass participation of students shows that $5 \%$ of that spread through real society, $26.8 \%$ spread through internet, and $68.17 \%$ through the interleaving of the two. Thus it can be seen that the last two ways are the main spreading media which have had significant impact on society. In dealing with this problem, on one hand, education and guide should be carried out on those who involved in the incidents, and the spreading way in society should be cut off. On the other hand, stricter regulation should be put on cyberspace information. Besides, relative department need to intervene and refute rumors in time so as to spread positive energy and prevent large scale cyberspace spreading of vicious thought and bad information.

\subsection{Time Length of the Incident (from the Birth to the Outbreak of the Rumor)}

The time length refers to the period from the birth of the rumor to its breakout. At the very beginning, the scale of participation is small. But with time going by, more and more people participate in that, and the scale of spreading become larger and the cause has bad influence in society. Investigation of the author shows that, at present, most network mass incidents $(84 \%)$ break out within 1 hour. $7.32 \%$ of the incidents beaks out in 1 to 3 hours. $7.32 \%$ breaks out in 1 week. $4.88 \%$ in 1 month. Thus we could see that the time length of incident breakout is short, but the impact is great. So, special department should be set up to intervene in the incidents, and attach great importance to the education and guide of students involved in the incidents. Besides, they should pay more attention to tracking and supervision, and focus on the feedback and explanation to harmful false information so as to prevent the wide spread.

\subsection{Ways of Dealing with the Incident}

Interviews shows that universities and colleges universally have in-depth studies on student sudden mass incident and have already established emergency response mechanism. With the mechanism, incidents can be properly dealt with in time with the coordination among student leaders, head-teachers, counselors, the school, relative student work department and security division. Timely educating and guiding students involved in the incidents will also be carried out. Besides, safety and stability of universities and colleges are ensured. At the same time, there also exists improper handling. Some universities and colleges did not attach enough importance to sudden mass incident, and intervene it in a simple rough way. This resulted in the further expansion of bad influence, such as the baneful influence in cyberspace and in real society.

\section{STRATEGIES AND SUGGESTIONS}

\subsection{Effectively Integrate internal and external class resources, Give Full Rein to Ideological and Political Education}

Universities and colleges should take full use of the effect of the first classroom teaching. Convey national laws and regulation and university rules and regulation in time during the freshmen enrollment education period. Guide students on correct treatment of network information, and teach them how to judge true and false of the information. Guarantee students do not trust and spread rumors. Besides, offer network information security course to students so as to teach them professional knowledge. Supervise and guide students' online behaviors. What's more, take various forms to develop rich and colorful second classroom activities, such as network security knowledge contest and web log competition. Relative department could set up online consulting platform to help students deal with the problems faced them. Guide them to communicate about their problems so as to avoid online accumulation and vicious spreading of online information.

\subsection{Intensify Classified Study on Mass incident, Improve Incident Dealing Mechanism.}

Based on the improvement of rules and regulations, we take the analysis and study on various sudden mass incidents as the first priority, and make a summary on different kinds of incidents so as to analyze the possible damage and make out plan to deal with them. Considering the time length from the incident's birth to the breakout is short, relative department should be assigned to be responsible for dealing with it. Training should be carried out to improve the response capacity. At the same time, enhancing cooperation and exchanges among universities and colleges is necessary. The department must regularly hold students' affairs exchange meeting to discuss and study students' related affairs, establish long term cooperative mechanism and intensify information sharing. Incident intervene group should be set up so as to take the responsibility of united coping with incidents in certain regions. Thus we can decrease the influence of incidents to the smallest extent.

\subsection{Broaden the Channel of Interest Demand, Preserve Students' Free Speech}

Generally, the reason that students use internet to express their interest demand and spread information 
is because of the lack of express channel in real society. Considering this, universities and colleges should establish perfect information express channel in accordance with the various interest demands of students. Such as, establishing university leaders' mailbox and e-mail, office open day, president reception day and regular interaction with students. Thus, interaction and communication with students can be enhanced, and timely responsing and dealing with the questions and advices from students so as to eliminate the hidden risk of students mass network incident.

All in all, in this era, intensifying study on university and college mass incident and correctly guiding students are of great importance to the stability of universities and colleges. It could also guarantee the order of teaching and scientific research, and finally help to realize the establishment of a harmonious university.

\section{REFERENCES}

[1] Hao Li. Study on Prevention Mechanism of University and College Mass Incidents under Network Environment:
Based on the Perspective of the Research of East China Normal University.2013.Zhejiang Academic Journal.

[2] Laihua Wang. Introduction to Public Opinions Research: Theory, Methods and Hot Spots. 2003.Tianjin: Tianjin Academy of Social Sciences Publishing House.

[3] Jianjun Ding. Analysis of the features, Cause and Response of University and College Network Public Opinion. 2008. Journal of Jingmen Technical College.

[4] Rui Chang. The research on Network Public Opinion of Group Event and its Governance Model and Mechanism.2012. Jilin: Jilin University.

[5] Shenghong Jiang. The present situation of the Network Public Opinion and guidance In China.2009.Guangxi social science.

[6] Mingzhen Chen, Zhengli Zhang. Prevention mechanism research on Group Events.2006. Journal of Yunnan Police officer College.

[7] Xinqi Yang. Thinking of the College Group Events.2006. Socialist research.

[8] Yuexin Lan, Xinyuan Deng. Emergency law research evolution of Network Public Opinion.2011.Intelligence magazine.

[9] Yali Long. Study on Early Warning of Network Public Opinion of College Students' Group Events.2011.Hunan: Hunan University.

[10] Zhiqiang Xiang, Yali Long. Study on Pre-warning of Network Public Opinion of University Students Mass Incident. 2011. Contemporary Communications. 